Jurnal Teknologi, 35(C) Dis. 2001: 35-44

(C) Universiti Teknologi Malaysia

\title{
PHASE MEASUREMENT OF ACOUSTIC WAVE PROPAGATION IN DOUBLE CHANNEL VIDEO BASED INTERFEROMETRY
}

\author{
YUSOF MUNAJAT $^{1} \&$ MOHAMAD KADIM SUAIDI ${ }^{2}$
}

\begin{abstract}
Abstrak. Phase measurement interferometer system was developed by modifying the phase difference between two outputs of Mach-Zehnder interferometer by approximately $90^{\circ}$ out of phase. System is developed in order to overcome some ambiguity of fringe shift in studying acoustic wave propagation and associate transient pressure profile. Two set of images were captured from two outputs of Mach-Zehnder interferometer in the event of with and without acoustic wave disturbance. The phase change over the interferograms were mapped and analysed separately and simultaneously. Simultaneous phase mapping gives better result and overcome ambiguity problem.

Keyword: Phase measurement interferometry, acoustic wave propagation.

Abstrak. Sistem interferometer pengukuran fasa telah dibangunkan dengan mengubahsuai perbezaan fasa antara kedua-dua output interferometer Mach-Zehnder sebanyak $90^{\circ}$. Sistem dibangunkan bagi mengatasi masalah kesamaran anjakan fasa dalam kajian perambatan gelombang akustik dan profil tekanan seketika yang wujud bersama. Dua pasang imej dirakamkan dari keduadua output interferometer Mach-Zehnder semasa adanya dan ketiadaan gangguan gelombang akustik. Perubahan fasa keseluruhan interferograms dipetakan dan dianalisa secara berasingan dan serentak. Pemetaan fasa secara serentak memberikan keputusan yang lebih baik dan mengatasi masalah kesamaaran.
\end{abstract}

Kata kunci: Interferometri pengukuran fasa, perambatan gelombang akustik.

\subsection{INTRODUCTION}

High speed optical study based on Mach-Zehnder interferometry system was developed in the laboratory [1,2]. The dynamic acoustic wave was studied using such the system and described in other paper [3]. There is a posibility to make full use of the two outputs of the interferometer. In the conventional Mach-Zehnder system the phase difference between two outputs are $180^{\circ}$. This is due to conservation of the energy. These two outputs signals can be modified to produce the phase difference of $90^{\circ}$ between the two outputs of the interferometer using non-polarising beam splitter [4]. Compare to other system [5] that is the polarising beam splitter was used;

\footnotetext{
${ }^{1}$ Department of Physics, Faculty of Science, Universiti Teknologi Malaysia, 81310, Skudai, Johor Bahru, Johor Darul Ta'zim.

${ }^{2}$ Faculty of Engineering, UNIMAS, 94300, Kota Samarahan, Sarawak, Malaysia.
} 
the s- and p- waves were not maintained. The advantage of having two sets of interferograms are to obtain more information of the phase change and overcome some ambiguity. The system developed offering the study of dynamic phase shifting interferometry with Fast Fourier Transform digital filtering. In this presents paper two sets of images were captured from two outputs of interferometer in the event of with and without acoustic wave disturbances. No parts of the optical component were moved. Abel Inversion technique was employed in the optical system to relate the phase changes of the interferograms due to the disturbance with the change in refractive index of the medium [6-7].

\subsection{THE CONCEPT}

Two signals from the interferometer can be represented as an intensity variations of the recorded interferograms. Each pixel of the recorded interferogram satisfies the intensity variations of the signal. Noise may appear during the capture of the signal. If disturbance introduce in the test arm of the interferometer where a test sample is located, the phase will change in both outputs of the interferometer. The signal in one of the outputs may change by $\sin (\Phi+\Delta \Phi)$ and the other one by $\cos (\Phi+\Delta \Phi)$. As the non-polarising beam splitter used in the system has a ratio of 50:50 at the wavelength of $514 \mathrm{~nm}$, the same intensities are produced in the sample and reference arm. Therefore the intensity variations of the two signals without disturbance can be represented as

$$
\begin{aligned}
& \mathrm{I}_{1}=\mathrm{I}_{\mathrm{o}}+\gamma \mathrm{I}_{\mathrm{o}} \sin (\Phi)+\eta_{1} \\
& \mathrm{I}_{2}=\mathrm{I}_{\mathrm{o}}+\gamma \mathrm{I}_{\mathrm{o}} \cos (\Phi)+\eta_{2}
\end{aligned}
$$

and the intensity variations of the two signals with disturbance can be represented as

$$
\begin{aligned}
& \mathrm{I}_{3}=\mathrm{I}_{\mathrm{o}}+\gamma \mathrm{I}_{\mathrm{o}} \sin (\Phi+\Delta \Phi)+\eta_{1} \\
& \mathrm{I}_{4}=\mathrm{I}_{\mathrm{o}}+\gamma \mathrm{I}_{\mathrm{o}} \cos (\Phi+\Delta \Phi)+\eta_{2}
\end{aligned}
$$

The phase change $\Delta \Phi$ evaluation can be obtained by using digital bandpass filtering to eliminate low frequency term, $\mathrm{I}_{\mathrm{o}}$ and both high frequency terms, $\eta_{1}$ and $\eta_{2}$. This can be done by using Fast Fourier Transform (FFT) filtering. $\gamma$ is the degree of coherence beam utilised in the interference beam. Consequently after filtering the equation (1) and (2) can be simplified as

$$
\begin{gathered}
\mathrm{I}_{1}{ }^{\prime}=\gamma \mathrm{I}_{\mathrm{o}} \sin (\Phi) \\
\mathrm{I}_{2}{ }^{\prime}=\gamma \mathrm{I}_{\mathrm{o}} \cos (\Phi) \\
\mathrm{I}_{3}{ }^{\prime}=\gamma \mathrm{I}_{\mathrm{o}} \sin (\Phi+\Delta \Phi) \\
\mathrm{I}_{4}{ }^{\prime}=\gamma \mathrm{I}_{\mathrm{o}} \cos (\Phi+\Delta \Phi)
\end{gathered}
$$


Each pixel of the recorded interferograms satisfies the intensity variation of the signals as $\mathrm{I}_{1}{ }^{\prime}, \mathrm{I}_{2}{ }^{\prime}, \mathrm{I}_{3}{ }^{\prime}$ and $\mathrm{I}_{4}{ }^{\prime}$ representing $\mathrm{I}_{1}{ }^{\prime}(\mathrm{x}, \mathrm{y}), \mathrm{I}_{2}{ }^{\prime}(\mathrm{x}, \mathrm{y}), \mathrm{I}_{3}{ }^{\prime}(\mathrm{x}, \mathrm{y})$ and $\mathrm{I}_{4}{ }^{\prime}(\mathrm{x}, \mathrm{y})$ respectively.

As a comparison to the technique to be developed, the equations (3) and (4) can be examined separately as two conventional methods. The phase was extracted from each of the interferograms and mapped separately as a set of interferometer A and $\mathrm{B}$. The phase of the interferogram with and without disturbance were compared. The phase difference due to disturbance in interferometer $\mathrm{A}$ as

$$
\Delta \Phi=\sin ^{-1}\left(\mathrm{I}_{3}{ }^{\prime}\right)-\sin ^{-1}\left(\mathrm{I}_{1}{ }^{\prime}\right)
$$

and from interferometer B as

$$
\Delta \Phi=\cos ^{-1}\left(\mathrm{I}_{4}{ }^{\prime \prime}\right)-\cos ^{-1}\left(\mathrm{I}_{2}{ }^{\prime}\right)
$$

The phase difference, $\Delta \Phi$ in equations (5) and (6) may give different results depending on the intensities variation $\mathrm{I}_{1}{ }^{\prime}, \mathrm{I}_{2}{ }^{\prime}, \mathrm{I}_{3}{ }^{\prime}$ and $\mathrm{I}_{4}{ }^{\prime}$ of the interferograms. Although the phase profile can be obtained from each of the interferogram by using FFT method, it was not enough in some cases due to the presence of extra fringes that give rise to an ambiguity.

The system was developed to obtain the phase change $\Delta \Phi$ simultaneously. The phase change $\Delta \Phi$ was then extracted and mapped simultaneously for each of the pixels. The phase change can be obtained by solving equations (3) and (4) as

$$
\Delta \Phi=\tan ^{-1}\left(\frac{\mathrm{I}_{3}{ }^{\prime}}{\mathrm{I}_{4}^{\prime}}\right)-\tan ^{-1}\left(\frac{\mathrm{I}_{1}^{\prime}}{\mathrm{I}_{2}{ }^{\prime}}\right)
$$

Using trigonometry relationship of tangent, the phase change from equations (3) and (4) becomes

$$
\Delta \Phi=\tan ^{-1}\left(\frac{\mathrm{I}_{2}{ }^{\prime} \mathrm{I}_{3}{ }^{\prime}-\mathrm{I}_{1} \mathrm{I}_{4}{ }^{\prime}}{\mathrm{I}_{1}^{\prime} \mathrm{I}_{3}{ }^{\prime}+\mathrm{I}_{2} \mathrm{I}_{4}{ }^{\prime}}\right)
$$

In the interferograms with a size of $256 \times 256$ pixels, the analysis can be done by vector line or matrix method. Equation (7) will be examined together with the equation (8) to observe the advantage of the method of phase measurement technique that we developed.

\subsection{SYSTEM ARRANGEMENT}

The arrangement was based on the Mach-Zehnder interferometry system as shown in Figure 1 [1]. The patterns of interference fringes were recorded by two mono- 
chrome Charge Couple Devices (CCD) camera with 256 gray scale. Acoustic wave propagation generated by a Nd:YAG laser was illuminated by a Dye laser at the wavelength of $514 \mathrm{~nm}$ and high speed temporal output of $1 \mathrm{~ns}$. It was synchronised precisely by a trigger unit. System was modified as to get the phase difference of approximately $90^{\circ}$ between two outputs of interferometer [4].

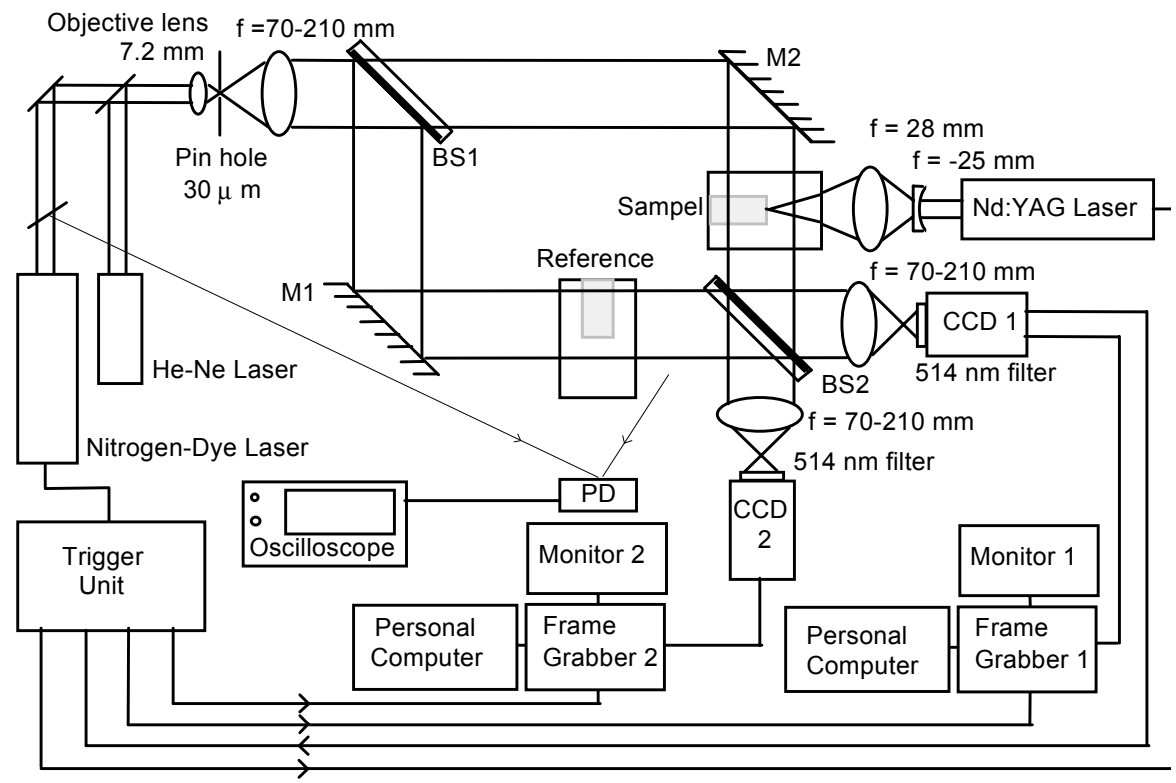

Figure 1 The Schematic of System Configuration Based on Mach-Zehnder Interferometer with Two Outputs

\subsection{RESULTS AND DISCUSSION}

Figure 2 shows the interferograms of laser interaction in air captured from both CCD A and CCD B at the time delay of $1.5 \mu$ s and $2.0 \mu$ s respectively. The energy of the Nd:YAG laser was set constantly at $3.7 \mathrm{~mJ}$. The size of the image was 768 pixels by 512 pixels. To analyse the digital image, this size was considered too large. Smaller size image, such as 256 pixels by 256 pixels was chosen to minimise the usage of memory space and reduce processing time. Figure 3 shows the region of interest disturbance interferogram of the CCD A and CCD B at the pixel of 256 pixels by 256 pixels. This region of figure 2 at the time delay of $1.5 \mu$ s was magnified.

It can be shown from figure 3 that the acoustic wave propagation at the delay time of $1.5 \mu$ s fulfilled the condition that the acoustic wave propagation being spherically symmetry. However, the disturbed interferogram A shows some effect of extra fringes in the area of disturbance as compared to the disturbed interferogram B (mirror image). This phenomena always happened at different delay time, fringe spacing 
a. Interaction in air at $1.5 \mu \mathrm{s}$

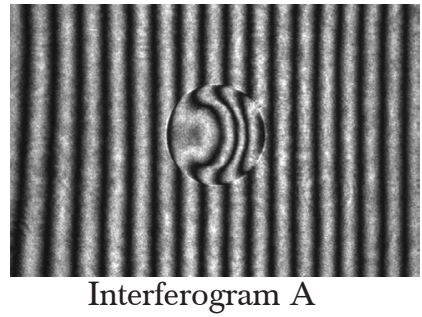

b. Interaction in air at $2.0 \mu \mathrm{s}$

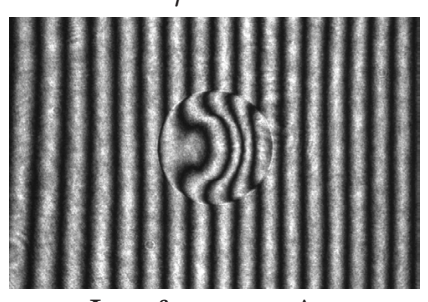

Interferogram A

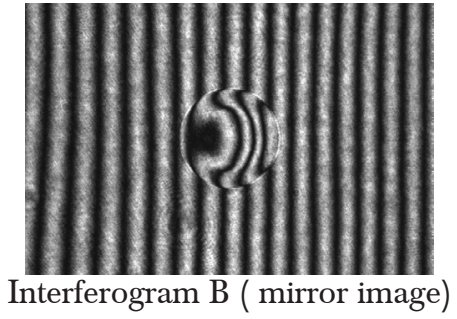

$\longleftrightarrow 5.0 \mathrm{~mm}$

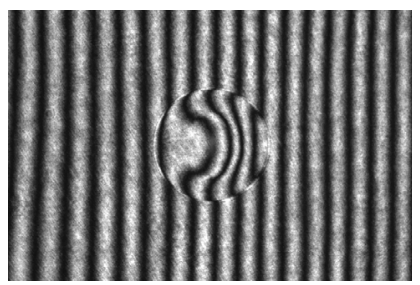

Interferogram B ( mirror image)

Figure 2 Images Captured from Both CCD A and B at the Time Delays of $1.5 \mu$ s and $2.0 \mu \mathrm{s}$.

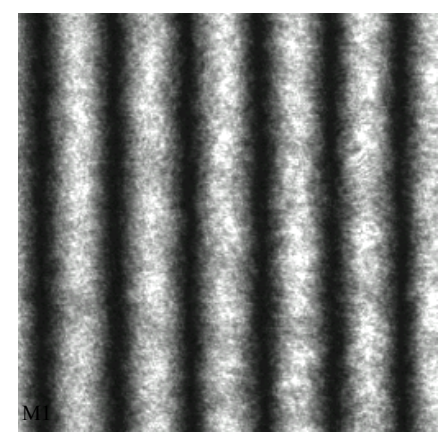

(i) Undisturbed interferogram A

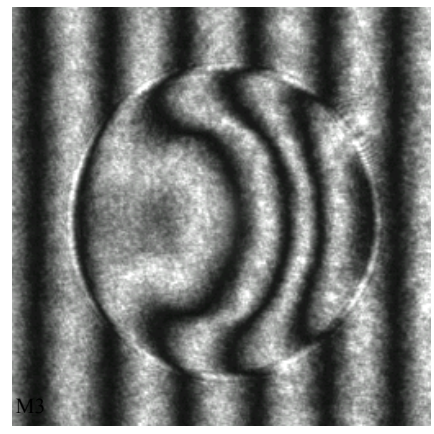

(ii) Disturbed interferogram A

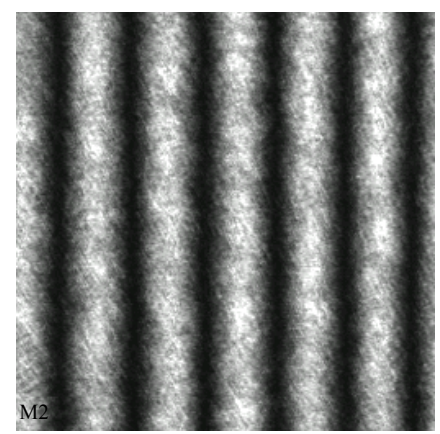

Undisturbed interferogram B (mirror image)

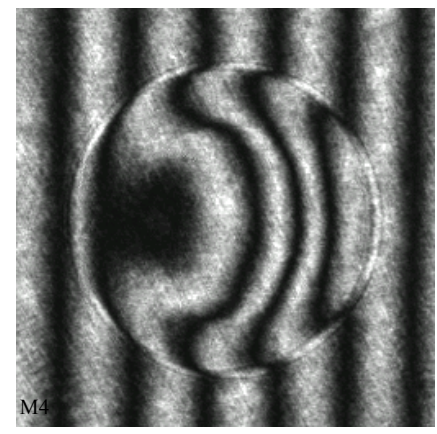

Disturbed interferogram B (mirror image)

Figure 3 Magnification of Figure 2a (i) Undisturbed Interferogram A and B. (ii) Disturbed Interferogram $\mathrm{A}$ and $\mathrm{B}$. 
and laser energy. This ambiguity was a problem and a single interferogram analysis was insufficient to map the phase change due to disturbance. In order to overcome the problem the phase quadrature technique was developed. This technique provides more information about the ambiguity of the phase change over the whole field of the interferogram.

After analysing the intensity variations of the center line of disturbance area, shown in Figure 4, phase spectrum of the intensity profile was obtained in the range of $-\pi$ to $\pi$. These wrapped phase profile was then unwrapped as to obtain a continuous phase profile with respect to pixel position. The phase mapping was done from left to right as proposed by Kreis [8].

The phase profiling of undisturbed image with equal spacing between the fringes is found to be linear. When disturbance occurred, the phase profile changed as indicate by the fringe shifted. The phase difference between the disturbed and undisturbed image gives phase change due to disturbance.

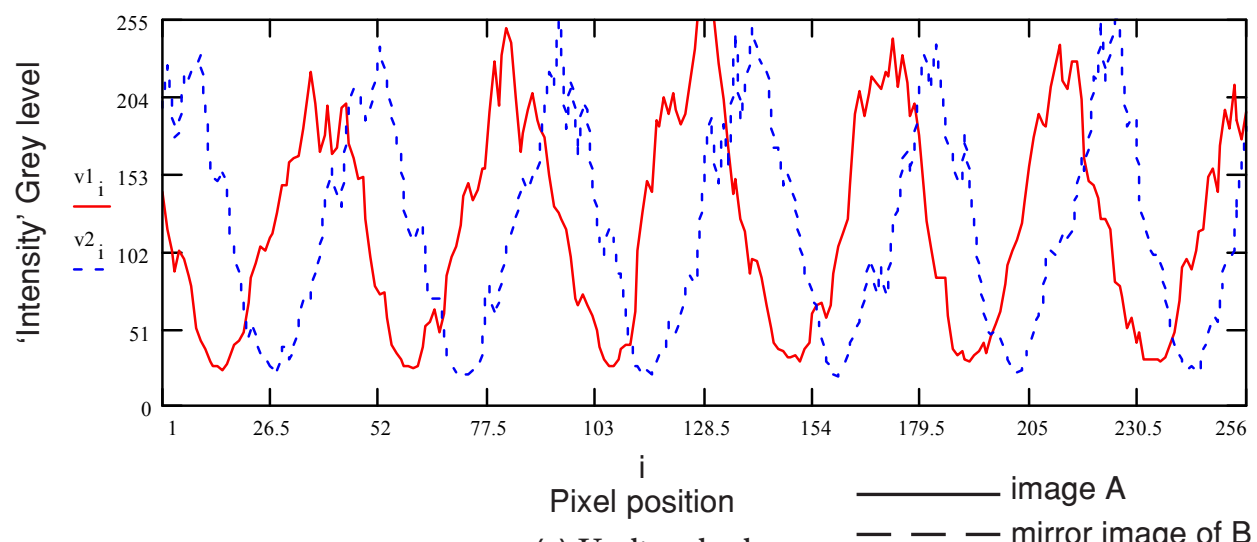

(a) Undisturbed

- - - mirror image of $B$

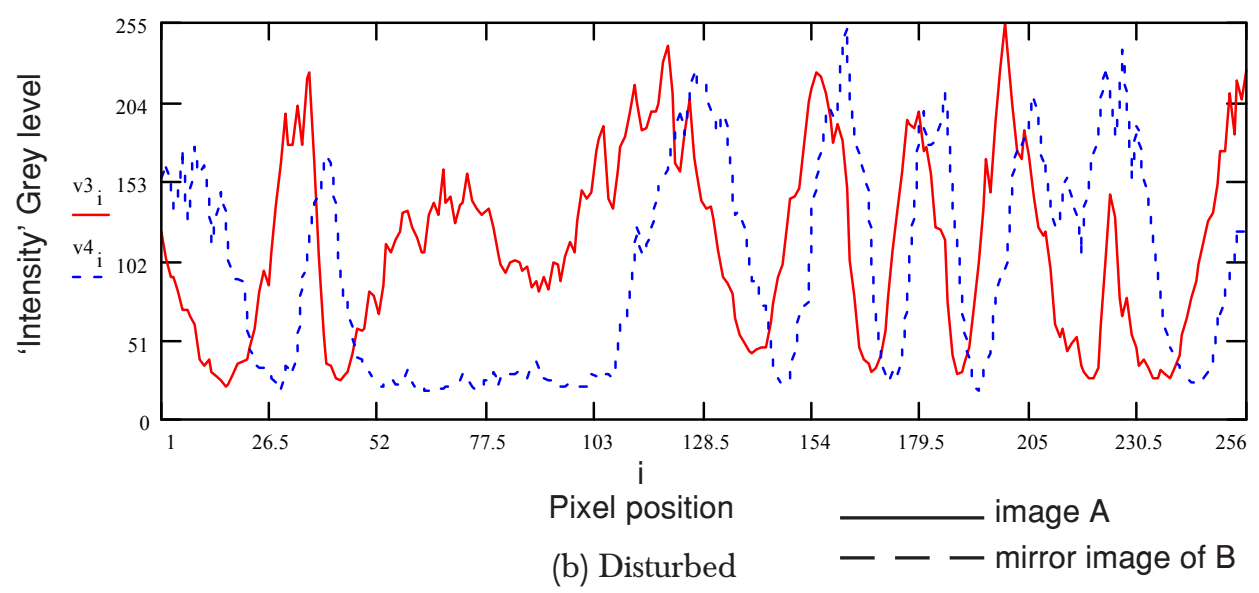

Figure 4 Profile of Interferogram A and Interferogram B (mirror image) at y $=128$ 


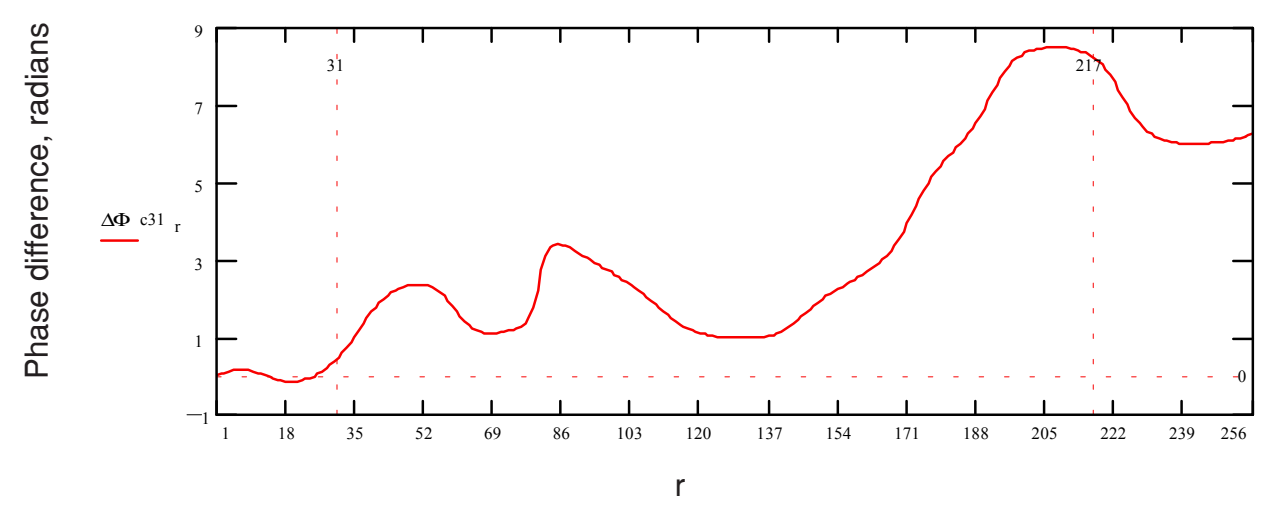

Pixel position

(a) Phase change

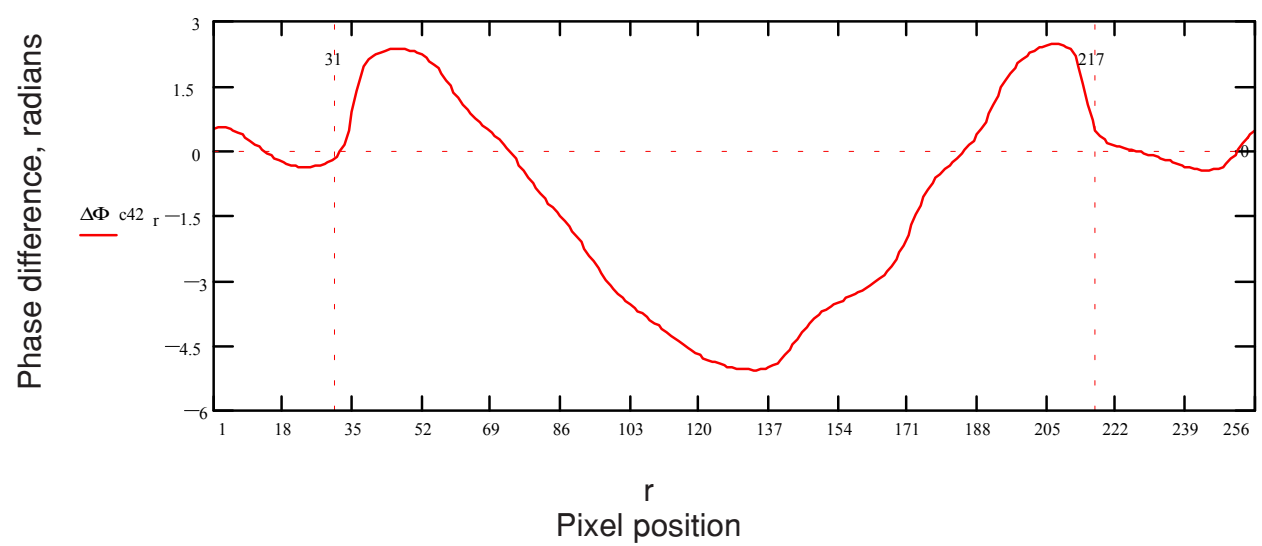

(b) Phase change

Figure 5 The Phase Change Obtained from the (a) Interferogram A and (b) Interferogram B (mirror image).

Figure 5 shows the profile of phase change of interferogram $\mathrm{A}$ and interferogram $\mathrm{B}$ (mirror image) in the center line of disturbance area $(\mathrm{y}=128)$. The phase difference in interferogram $\mathrm{B}$ shows a good phase profiling as compared to interferogram A. Different sets of interferograms captured by CCD A and CCD B may give a good phase profiling in the interferometer $\mathrm{A}$ and vice versa.

The phase change in equation (7) and by using separate phase mapping is shown in Figure 6 as a comparison. The phase was mapped individully for each of the disturbed and undisturbed interferogram. There was a good phase profiling for almost all pixel position, except phase change at the pixel positions between 69 and 


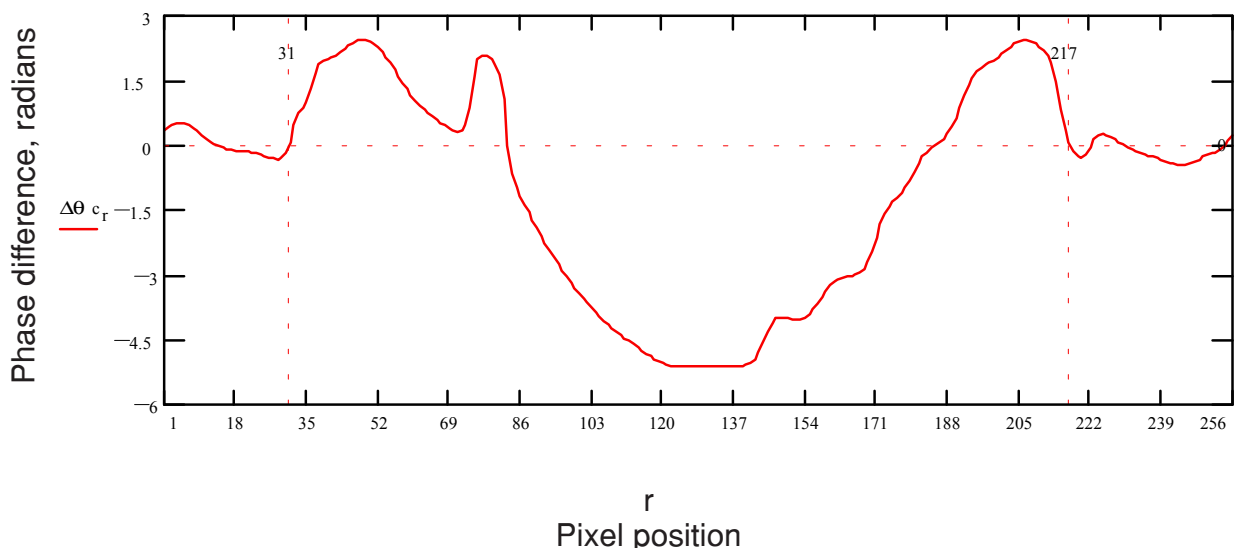

Figure 6 The Phase Change of Undisturbed and Disturbed of Phase Profile as a Comparison

86. There was the effect of an extra number of fringes in the area of disturbance compared to the outside.

Another phase mapping method was proposed which based on the simultaneous phase mapping. The phase was extracted and mapped simultaneously for each of the pixels. Although the wrapped phase profile derived from equations (7) and equation (8) have different phase spectrum; the unwrapped phase change profile gave the same result as shown in Figure 7. Although the acoustic wave propagation was spherically symmetry, the phase change profile on the left side was better than that on the right (see Figure 7). The left side has a better spatial resolution compared to the right side as shown in Figure 3.

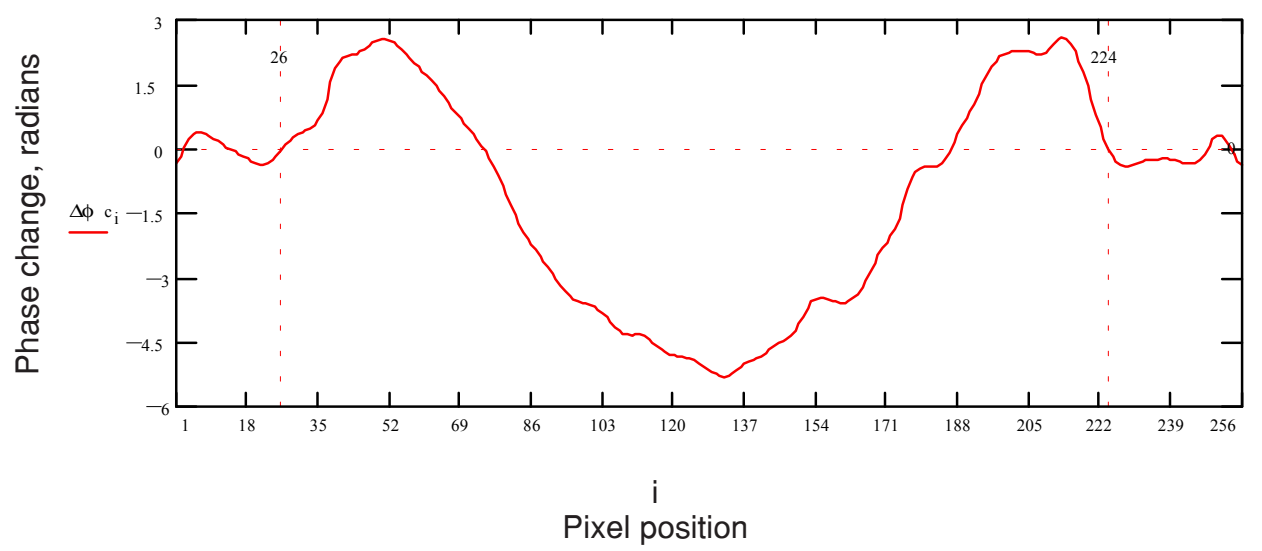

Figure 7 The Unwrapped Phase Profile by Simultaneously Phase Mapping 


\subsection{CONCLUSIONS}

High speed and high resolution optical detection system based on two outputs of Mach-Zehnder interferometry system was successfully developed. The system enable to overcomes the ambiguity of the phase change due to acoustic wave disturbances induced by laser interaction. The phase measurements can be made more accurate if the fringe distribution satisfies the frequency condition. If the spatial frequency of the fringe pattern is high, the measurement of fringe shift becomes more valid, but in the phase measurement becomes more ambiguous.

\subsection{ACKNOWLEDGMENT}

The authors would like to express their thanks to Prof. Dr. D.C.Emmony and Dr. Yonghua Jin from Loughborough University of Technology for their useful discussions. Thanks are also due to UTM and RMC for supporting this work under RMC Vot No 71540.

\section{REFERENCES}

[1] Yusof Munajat, Mohamad Kadim Suaidi. 1999. Optical Detection and Video Imaging of Laser Interaction. Jurnal Fizik UTM. 6(1), UTM.

[2] Yusof Munajat, Mohamad Kadim Suaidi. 1999. Synchronisation of Trigger Unit in Laser Interaction. Jurnal Fizik UTM. 6(1), UTM.

[3] Yusof Munajat, Mohamad Kadim Suaidi. 1999. The Generation and Propagation of Acoustic Waves in Some Medium. Jurnal Fizik UTM. 6(2), UTM.

[4] Yusof Munajat, Mohamad Kadim Suaidi. 2000. Modified Phase Difference between Two Outputs of Mach-Zehnder Interferometry. Jurnal Fizik UTM. 7(2), UTM.

[5] Smythe, R., and R. Moore. 1984. Instantaneous Phase Measuring Interferometry. Opt. Eng. 23(4): 361.

[6] Wing, W.R. and R.V. Neidigh. 1971. A rapid Abel inversion. Am. J. Phys. 89; 760

[7] Ward, B. 1991. Generation of Acoustic Waves by Focused Infrared Neodymium-Laser Radiations. Ph.D. Thesis. Loughborough University of Technology, UK.

[8] Kreis, T. 1986. Digital Holographic Interference-Phase Measurement Using the Fourier-Transform Method. J. Opt. Soc. Am. A. 3 ; 847. 